\title{
Appraisal of Contract Administration Protocols for Successful Project Undertakings
}

\author{
Yehualashet Getahun Ayele \\ College of Business and Economics, Addis Ababa University, Addis Ababa, Ethiopia
}

Email address:

getyehuall@gmail.com

To cite this article:

Yehualashet Getahun Ayele. Appraisal of Contract Administration Protocols for Successful Project Undertakings. International Journal of Finance and Banking Research. Vol. 6, No. 6, 2020, pp. 102-110. doi: 10.11648/j.ijfbr.20200606.11

Received: August 1, 2020; Accepted: October 14, 2020; Published: December 4, 2020

\begin{abstract}
This study is intended to fill a gap in the literature on contract administration protocols. Since no organization is self-reliant, often the acquisition of sought after resources and efforts from external sources come true through contractual agreements of some form. Thus, in a project environment, there are array of contracts which are perceived as important instruments that direct and govern every project move. This, as a result, demands well-established contract administration protocols. Contract administration is a collaborative effort to accomplish clearly stipulated contract objectives. Since coordination and teamwork are extensively thought to be important contributors to success, the importance of having well-developed contractual agreements among contracting parties and good contract administration protocol is indisputable. For change trends in the business environment show that the contractual relationships between parties to a contract are likely to become more multifaceted in the future, everything possible should be done to minimise the number of disputes and the impact they may have on the performance of projects. For this effect, the parties to a contract should have better appreciation of contract conditions and their interpretations. Besides, the data analysis of this research revealed that 'Statement of work', 'Work schedule', and 'Performance reporting' are the top three most important considerations to be deliberated while constructing good contract content. It also disclosed that effective contract administration can be realised only if both parties to the contract observe the terms and conditions of the contract and adhere to their rights and obligations, as appropriate. In addition, contract administration practices can be enhanced if both parties demonstrate a reasonable level of flexibility accompanied by the willingness and the ability to adapt the contract terms to reflect changing circumstances. Likewise, systematic and efficient planning, execution, monitoring, and evaluation activities boost contract administration protocols. Most importantly, 'adequate planning and explicit specifications' followed by 'good governance and clarity of responsibilities' were nominated by quite significant of the respondents as demonstrated or tested strategies for enhanced contract administration protocol. On the other hand, this research also uncovered that contract administration can be used as an imperative tool to mitigate fraud and corruption. Likewise, the study discovered evidences for the existence of proven strategies that enable to manage contractual disputes effectively and efficiently. Finally, after extensive analysis of the data, operational techniques of using contract administration as a tool for successful project undertakings have emerged as the most attention worthy finding of this study.
\end{abstract}

Keywords: Contract, Contract Administration, Contract Administrator, Dispute, Dispute Resolution

\section{Introduction}

More often than not, a project is a collection of smaller projects - each of which has its own outcome [7]. It is the effective integration of these outcomes that makes a project successful. In a few words, a project requires a collective effort for its successful completion. The best project outcome occurs when there is synergistic teamwork with each team member contributing to the effort and each team member's quality of contribution being enriched or enhanced as a result of ideas and stimulus others bring to the process. In brief, a project is a teamwork performed by different parties that have stakes in it [5]. This, as you would expect, requires a contractual agreement between the parties that perform each smaller project - which finally come together to make up the big project. Therefore, entering into contractual agreements of varies kinds is an ordinary routine in the wide setup of project management.

Because an agreement involves an exchange of promises or 
goods, it takes at least two parties to make an agreement [3]. One party offers, and the other accepts the offer. Now, the agreement is legally binding and is therefore a contract. Unless there is an agreement between the parties involved, on all the essential terms, the law does not recognise the existence of a contract. In brief, there is a contract only if the rights and obligations of the parties to the contract are explicitly stated and an agreement is reached between them. Everything considered, a contract is an agreement that is legally binding. A contract may be written or unwritten; 'express' or 'implied' respectively [14]. A contract may also be partly written and partly oral or implied.

Projects of all form and size involve plentiful individual contracts. Since contracts establish the rights and obligations of the parties involved and the procedures for administration, they allow for accountability. In other words, a valid contract is an agreement made between two or more parties whereby legal rights and obligations are created which the law will enforce. Thus, in a project environment, contracts are perceived as important instruments of achieving the big project objective. Therefore, contracts are vital to the project delivery process. A contract creates/covers the obligation to undertake a certain project and the right to payment for the agreed upon amount. The principal's right to compensation for defects is also created by a contract [1]. Generally, contracts direct and govern every project move.

Since contracts are common gadgets of every project activity or move, contract administration is becoming an integral part of project management. As a consequence, in today's business in general and projects in particular, contract administration has emerged as a complex but a strategic matter of importance. It is also likely that some co-ordination and contractual problems are bound to occur, resulting in claims and disputes. As such, many concerns, disputes, demands and questions are frequently raised on the subject. Therefore, contract administration is in the core of running projects.

Nowadays, because the globe has been integrated as never before, the world has become like a small village. This, in consequence, has resulted in a world that is so strongly interrelated and dependent on one another. As a result, the business environment is getting more complicated and so are the laws. In the past contracts needed only to deal with the laws in one country [6]. These days; however; international trade laws have to be taken into account when developing contracts. In this regard, the prevailing dispute between Ethiopia and Egypt on the Great Ethiopian Renaissance Dam (GERD) is a good indicator for the interdependency of nations of the world and hence for the need to consider international trade laws when dealing with project contracts. Besides, parties to project contracts are also becoming more aware of their rights and responsibilities, thus demanding and negotiating for better contracts for themselves. Furthermore, increases in contract volumes and complexity of transnational contracts have resulted in an increasing recognition of the importance of effective contract administration.

To sum up, there are almost innumerable variations between project contracts and their administrations, but the variations are not departures from the basic principles. If the basic principles are understood, the significance of the variations will become apparent. On the other hand, since coordination and teamwork are extensively thought to be important contributors to project success, the importance of having well-developed contracts and good contract administration is crucial. Therefore, the fundamental purpose of this research is to impart its share in the development effort of a strong project professional that is well grounded in the basic principles of contract and contract administration.

\section{Statement of the Problem}

Projects bring together resources, skills, technologies and ideas to deliver organizational benefits or to achieve project objectives [8]. Good project management helps to ensure that these benefits or objectives are achieved within budget, within time and to the required quality [9]. Therefore, project management is a function that coordinates the efforts of different human and material resources available to accomplish project goals and objectives efficiently and effectively. However, no organization has all the resources and efforts required to do everything needed to achieve project objectives, but only few of them. Therefore, additional resources and efforts required for the completion of projects must be bought in from external sources. Quite often, the acquisition and coordination of these resources and efforts come true through contractual agreements of some form. In the light of this, a contract is a mutually binding legal relationship obligating one party to the contract to furnish the supplies or services and the other to pay for the price for them $[2,4]$. Thus, a contract is the mechanism by which the project organization is created, project managers are employed, goods and services are procured, and the commercial nature of the project process is defined [13].

For changes in the business environment show that the contractual relationships between the parties to a contract are likely to become more multifaceted in the future, every effort should be made to minimise the number of claims and disputes and the impact they may have on the performance of the project. To achieve this, the parties to a contract should know the legal principles governing the formation of contracts. They should also have better appreciation of contract conditions and their interpretation and a greater awareness of the implication of inequitable allocation of risks and the need for more efficient and effective procedures for administering contracts.

Often a project incorporates a strange array of contracts and intense competitions between proponents of various forms of contracts. Evidently, this demands well-established contract administration. Contract administration is a process that begins from the award of contract and extends to the completion of the work or its termination [15]. Hence, contract administration refers explicitly to the process in which an already developed and initiated contract is administered. In other words, it is the process of managing contract implementation to ensure the efficient and effective delivery of the contracted project outcomes. Thus, it is a 
primary part of the procurement process that assures the project owner gets a quality project outcome for what it has contracted and assures that users are satisfied with the final product. Its focus is on overseeing the activities that are undertaken during the contract implementation phase, following the award of contract. In brief, contract administration is the process of ensuring that the seller lives up to the terms of agreement in the contract [10]. On the other hand, the project manager and the contract administrator must work together to make sure that the seller meets its obligations. But if the seller doesn't meet its contractual agreements, disagreements and/or termination of the contract may proceed; and then legal remedies may ultimately be pursued.

Contract administration ought to be objective and reference based. Incontrovertibly, the objective reference used for effective contract administration is the contract itself - which states the rights and obligations of the parties to the contract and governs their acts. Therefore, the acts of both parties should be in accordance with the terms of contract. Consequently, to achieve good contract performance, contractors should ensure that the terms of the contract are observed and that both parties to the contract understand their respective duties and responsibilities. Contract administration should also involve some level of flexibility by both parties and give a room to adapt the contract terms to reflect any changing circumstances, as appropriate [11]. Besides, contract administration can be strengthened by systematic and efficient planning, execution, monitoring, and evaluation of it. Likewise, the success of contract administration can also be enhanced by other activities such as choice of contract type, contractor selection, and contract administrator appointment phases.

Good contract administration practice demands timely identification of issues and their operational management. For this effect, contract administration mainly seeks to monitor project progress against the terms of the contract by comparing measured performance to established standards via putting open communication in place throughout the process. The terms and conditions of the contract should also provide a suitable contractual framework that enables the introduction and performance of appropriate remedies to best resolve issues that may arise [12]. On the other hand, contract administration should be economically feasible. Thus, the human and material resources applied to manage a contract ought to be proportional to the size, scope, complexity, duration, risk, and strategic importance of the contract. Here, it is important to note that one size does not fit all.

On the other side of the spectrum, virtuous stakeholder management is one of the essential skills required of contract administrators for successful project undertakings. This demands rational assessment of the nature of different types of relationships with different stakeholders, perhaps each having its own interest that may contradict with the interests of other stakeholders. Hence, for the best result possible, the contract administrator should identify how much time and resources should be committed to communicating and handling each stakeholder. Because each contract is different, careful considerations of the stakeholders involved, the nature of the contract, and its value, scope and complexity need to be taken into account when developing a relationship management strategy, as part of the contract administration plan.

\section{Basic Research Questions}

A. What considerations contribute most to the apt choice of contract type?

B. What is the current applicability and success level of contract administration?

C. How is contract administration used as a mechanism to mitigate corruption?

D. What are the key responsibilities and roles of a contract administrator?

E. What are the qualities of a good contract administrator?

F. How can a contract administration protocol be improved?

G. How should contractual disputes be managed?

H. How can contract administration be used as a tool for successful project undertakings?

\section{Research Objectives}

\subsection{General Objective}

Since there is no one best way of contracting, this research aims to help practitioners to find the best contract for a particular project and (having chosen it) administer it efficiently. Therefore, the general objective of this research is to review common contract administration protocols and develop a comprehensive and effective contract administration framework that ensures successful project undertakings.

\subsection{Specific Objectives}

The following explicit objectives of the research have been addressed in this study.

1. To scrutinise considerations that best contribute to the apt choice of contract type;

2. To investigate the current applicability and success level of contract administration;

3. To examine possible techniques of using contract administration as a mechanism to mitigate corruption;

4. To identify key responsibilities and roles of a contract administrator;

5. To discover typical qualities of a good contract administrator;

6. To develop ways of improving contract administration protocols;

7. To review strategies of managing contractual disputes, and

8. To device techniques of using contract administration as a tool for successful project undertakings.

\section{Significance of the Study}

This study introduced new dimensions into one of the key 
strategic aspects of importance in project management, contract administration. It discussed the significances and challenges of contract administration as its central subject of discussion. Then, based on extensive investigations, new insights into the choice of contract type, the roles and responsibilities of contract administrators, techniques of improving contract administration protocols, strategies of managing contractual disputes, and finally contract administration as an important tool of successful project undertakings are thoroughly discussed in the study.

The study was carried out with the superseding objective of helping its readers to better comprehend the art and science of contract administration. It is also expected to serve its readers as a guide to sidestepping possible situations where contract administration affiliated problems are likely to arise. Equally, it is also designed to help practitioners in the area to acquaint themselves with the basics of contract administration; and be better informed about relationship management schemes for effective contract administration. In addition, this research is directed to project sponsors, performing companies, project managers, beneficiaries, lawyers, students and others involved in contract administration, in one way or the other.

It is also understood that good contract administration enables companies to execute projects according to their plan and within predetermined project specifications. This, in turn, enables them to complete projects effectively and efficiently. Therefore, the research is significant in a way that it enhances project success thereby enlightening practitioners on effective contract administration strategies.

Generally, this research is of vital importance as it clearly depicted the impact of contract administration on project undertakings, evaluated the prevailing applicability and success level of contract administration, proposed operational techniques of managing contract stakeholders, and outlined effective practices for resolving contractual disputes that may arise during project undertaking activities. In a nutshell, since contract administration is a multifaceted and strategic subject in project management, practitioners and researchers in the area frequently raise various questions and concerns on the subject that have to be addressed through responsible investigations like this. Therefore, this study is a dependable effort on the side of the researcher to address the questions and concerns raised with a sense of responsibility.

\section{Major Research Findings}

Here, it is worth to mention that the validity of the questionnaire was checked using Cronbach coefficient and a value of 0.82 was attained, which is considered relevant and shows that there is good adherence from questions to the constructs. Moreover, to make sure that the best possible quality of data is utilized as input for the research, all completed questionnaires were checked for their integrity, accuracy, relevance and completeness. Then, all questionnaires not meeting these criteria were rejected to make the research findings more reliable and dependable.

There is no doubt that proper construct of contracts plays a central role in the process of contract administration. Contract administration is only as simple as the clarity and comprehensiveness of the terms of the contract. In essence, the contract administration process becomes at its ease only if the content of the contract is very pragmatic and far-reaching. Therefore, it is indubitable that a range of key considerations should be taken into account when designing/constructing a contract that is more likely to streamline its administration later on. Hence, in this study each research participant was asked to nominate his/her top three considerations for constructing decent contract content. Accordingly, the data analysis of the research revealed that 'Statement of work or deliverables', 'Work Schedule', and 'Performance reporting' were mentioned as the first three most important considerations or inputs to be considered while constructing good contract content. In the light of this, Figure-1 below demonstrates the top ten vital considerations necessary for good contract content, as revealed by the data analysis.

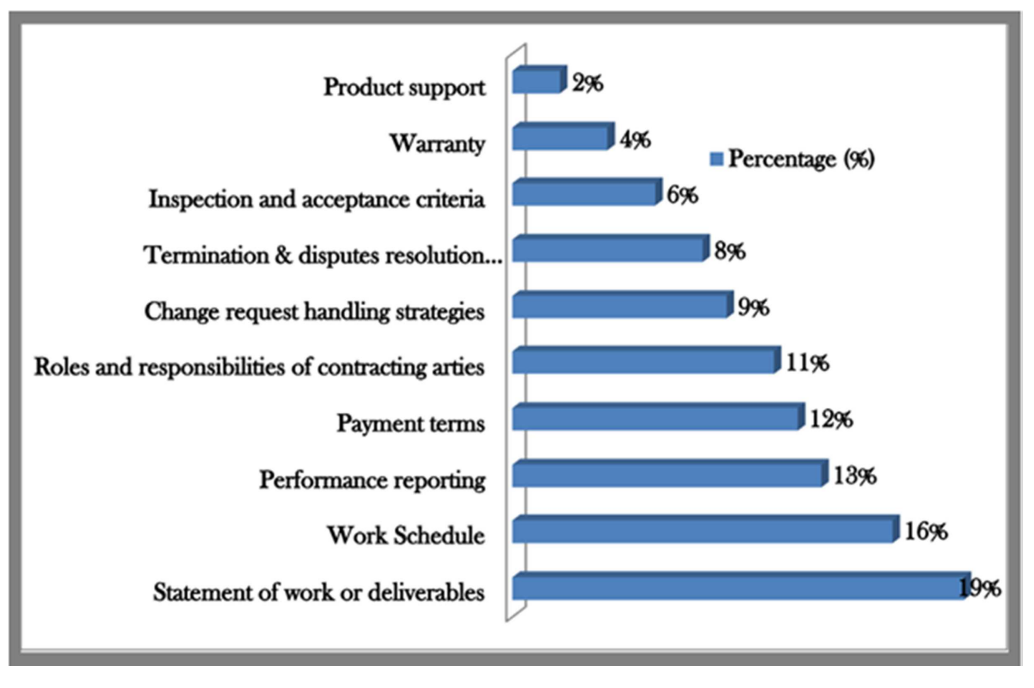

(Source: Own Survey)

Figure 1. Top 10 considerations that best contribute to the right choice of contract type. 
Further analysis of the data also revealed that the current applicability level of contract administration is extremely unreliable. Knowledge is one thing but action is another. Knowledge by itself is of no value; but its application. That is, it is not having good understanding about a certain subject that matters but it is the willingness and the ability to put it into action. Action is everything as nature does not reward passive spectators. In brief, a brilliant idea or an outstanding understanding but not yet (in the right shape and form to be) put into practice is worthless. Therefore, the applicability of knowledge is of vital importance. Accordingly, this research has investigated the current applicability level of contract administration; and has discovered the prevalent inconsistency as shown on the figure below.

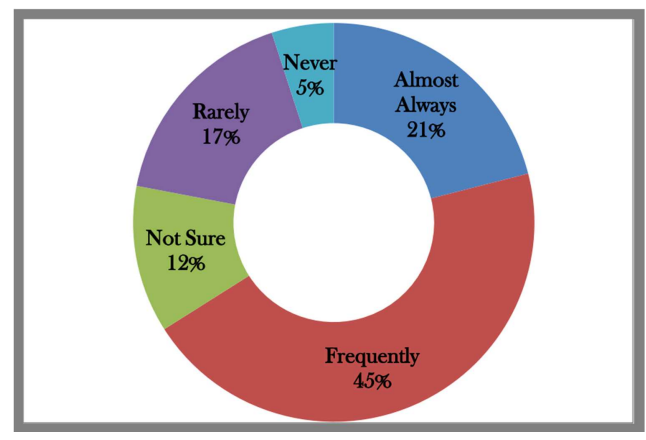

(Source: Own Survey)

Figure 2. The current applicability level of contract administration.

By the same token, the prevailing/current success level of contract administration was also examined. As the figure below disclosed, there is substantial challenge in the contract administration effort/process of most projects. This is why $45 \%$ of the contract administration efforts were either unsuccessful $(26 \%)$ or very unsuccessful $(19 \%)$. Clearly, this is a major area of concern for both researchers and practitioners.

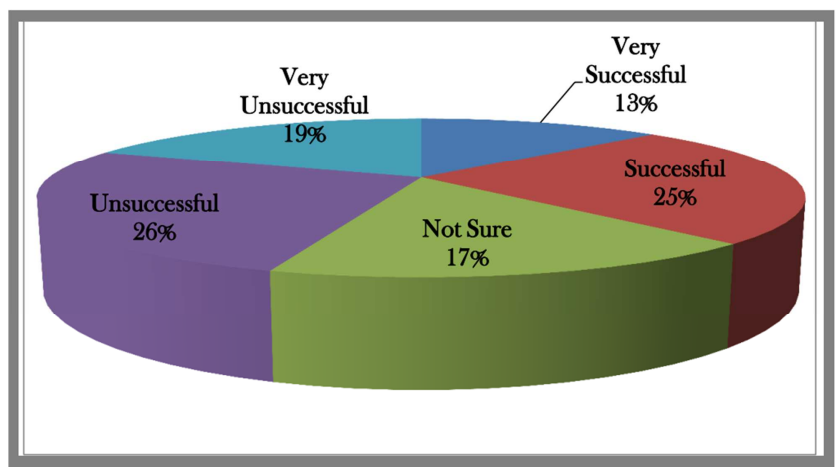

(Source: Own Survey)

Figure 3. The prevailing success level of contract administration.

On the other hand, this research also uncovered that contract administration can be used as a tool to mitigate fraud and corruption. Ordinarily, contract administration requires contracting parties and all those that are involved in the delivery of the contract to observe the highest possible standards of ethics; and refrain from any act of fraud and corruption during the entire contract execution process. Therefore, all parties involved in the execution and management of contracts are expected to hold themselves and their staff to the highest levels of integrity and professional conduct. Besides, any form of attempt to impede or obstruct the exercise of the contract administrator's inspection or his/her audit rights constitutes a fraud and corruption with all the consequences. To sum up, the table below portrays how contract administration can be used as a tool to mitigate the acts of fraud and corruption.

Table 1. Possible techniques of using contract administration as a tool to mitigate fraud and corruption.

\begin{tabular}{lll}
\hline S/N & Contract administration can be used as a tool to mitigate fraud and corruption by giving room to: & \% \\
\hline 1 & Inspect the execution and/or the accounts and records & 22 \\
2 & Inspect quality of materials and/or workforce & 15 \\
3 & Justify change orders in terms of terms of the contract & 14 \\
4 & Review changes in the terms and conditions of the contract & 11 \\
5 & Make payments only in accordance with the terms of the contract & 10 \\
6 & Control false or duplicate invoices & 8 \\
7 & Promptly report any suspicious F \&C related activities & 7 \\
8 & Take appropriate remedial actions whenever Fraud and Corruption (F \& C) is suspected & 6 \\
9 & Observe the highest standards of ethics and refrain from F \& C & 4 \\
10 & Discharge responsibilities within the boundaries of the contract & 3 \\
\hline
\end{tabular}

(Source: Own Survey)

The table above discloses the ten most mentioned techniques (along with their percentage) of using contract administration as an important instrument to mitigate fraud and corruption.

In addition, the contract administrator also oversees the entire contract in accordance with the contract documentation and the program scheme. Basically, the contract administrator is responsible for administering the terms and conditions of the contract between the contracting parties. Besides, the administrator also has two distinct functions: an agency function, and a decision-making function. Therefore, the administrator acts as the agent of the employer in some situations but will also be required to make decisions in others. Hence, the administrator has 'dual' role that often contradict with one another.

Here it is important to mention that every so often parties to the contract have contradictory interests. Nevertheless, the administrator has both agency function and decision-making 
function. But the decision-making should reflect the contract administrator's professional expertise and hence should always be impartial notwithstanding the agency function of the contract administrator. This, without a shadow of doubt, puts the administrator in a challenging position. More explicitly, the administrator's key responsibilities as contract administrator involve:

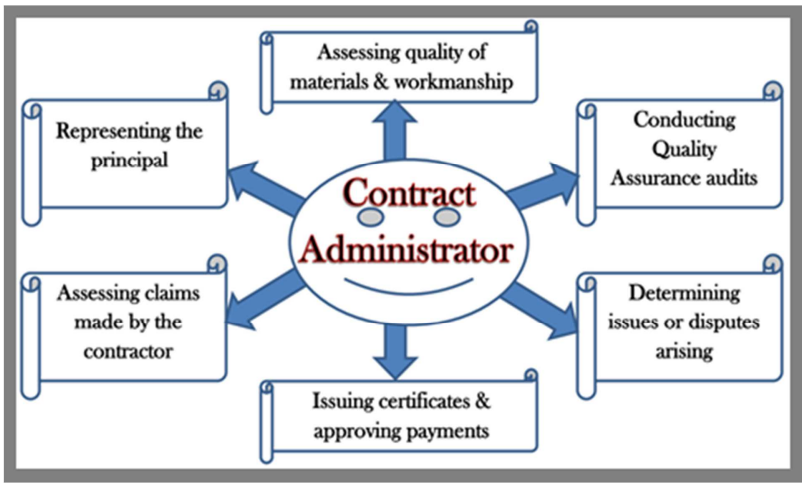

(Source: Own Survey)

Figure 4. The key responsibilities of a contract administrator.

Even though the figure above depicts only the most important responsibilities of a contract administrator, he/she is also responsible for making assessment of progress claims and then issue progress certificates. The administrator is also responsible for reviewing claims for extra payment and inspecting schedule extension requests for variations to the contract.

Likewise, the study also investigated the key roles of contract administrators. In principle the role of the contract administrator commences only after a contract is in place between the parties to the contract. Yet in practice the duties of the contract administration commences long before the contract exists because often there is an implied requirement for the contract administrator to perform pre-contract services.

The contract administrator has a key role in making a fair determination of matters or claims raised, in accordance with the contract, and taking due regard of all relevant circumstances. When carrying out his/her duties, the administrator has to act neutrally between the contracting parties and shall not be deemed to act for the Employer. The figure below displays only the most important roles of the CA.

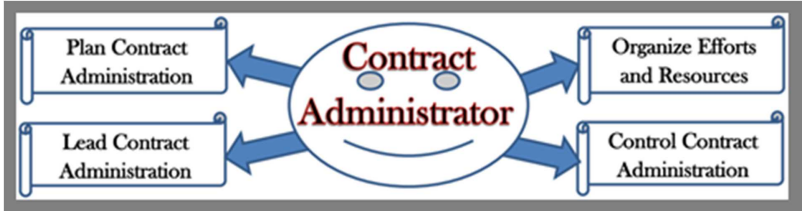

(Source: Own Survey)

Figure 5. The key roles of a contract administrator (ca).

This paper has also examined the most strategic qualities of contract administrators that add value to the whole process of contract administration. It is obvious that for effective contract administration, the contract administrator needs to have the appropriate quality (including the right mix of qualifications, skill \& knowledge, and experience). The administrator should also have an appropriate mix of hard and soft skills. However, the relevant mix of skills depends on the nature and complexity of the contract, the levels of risk, and the actual operating environment.

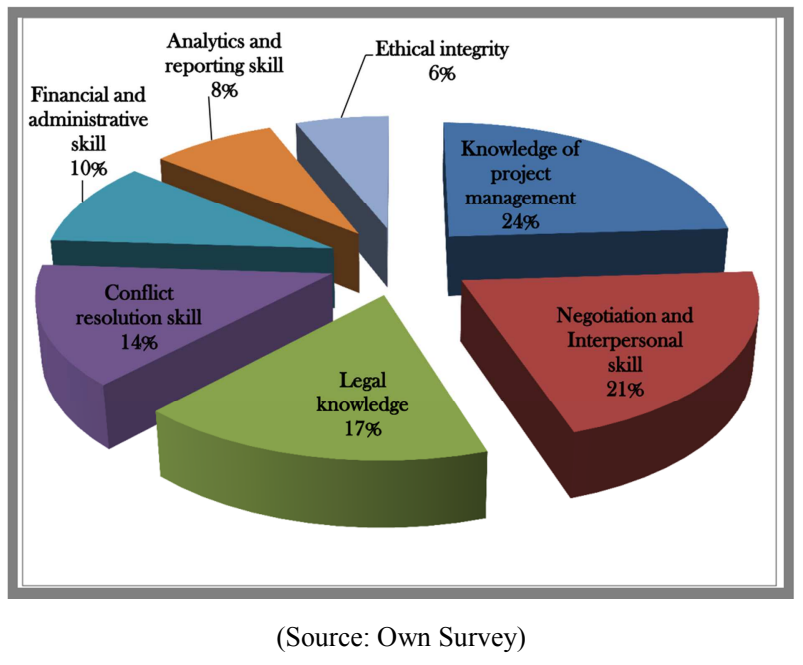

Figure 6. The most strategic qualities of a good contract administrator.

Most importantly, the data analysis process revealed imperative techniques that can be applied to improve the contract administration protocol. Accordingly, effective contract administration can be realised only if both parties to the contract observe the terms and conditions of the contract and adhere to their rights and obligations, as appropriate. Besides, contract administration practices can be enhanced if both parties demonstrate a reasonable level of flexibility accompanied by the willingness and ability to adapt the contract terms to reflect changing circumstances. Likewise, systematic and efficient planning, execution, monitoring, and evaluation activities boost contract administration protocols. Finally, this study also revealed timely identification and management of issues as another important administrative effort that can improve contract administration practices.

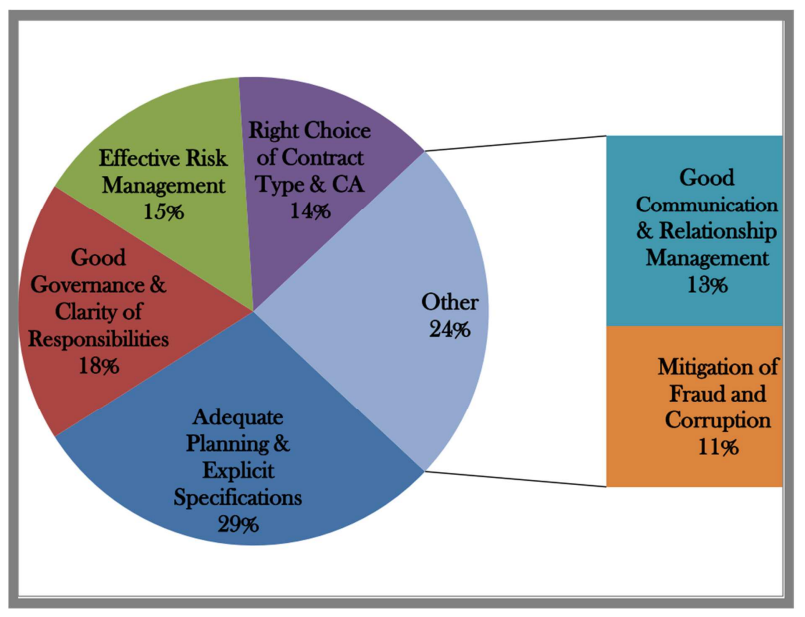

(Source: Own Survey).

Figure 7. Suggested schemes/tactics for improved contract administration protocols. 
As shown on the figure above, 'adequate planning and explicit specifications' (29\%) followed by 'good governance and clarity of responsibilities' (18\%) were mentioned by quite significant of the respondents as demonstrated or tested strategies for enhanced contract administration protocol.

On the other side of the spectrum, the data collected for the purpose of this study revealed evidence for the existence of proven strategies that enable to manage contractual disputes effectively and efficiently. A contract is nothing but a legally binding relationship between contracting parties. Like all other relationships, contracts may also go wrong. All contracts, no matter how carefully worded and prepared, are subject to some form of dispute or disagreement among contracting parties sooner or later. In addition, it is virtually impossible to negotiate a contract that anticipates every potential scenario of disagreement between the parties. However, experiences show that the more complex the nature of the contract and the greater the monetary value involved in it, the more likely it is that future disputes over interpretation of the terms and conditions will occur. Over and over again, many disputes arise simply because one party or both parties rely solely on rights or remedies spelt out in the contract. Therefore, nowadays, disputes and dispute resolutions are becoming common gadgets and unavoidable scenarios in almost all contract administration practices. Thus, it is wise to think of disputes and dispute resolution strategies before they began to uncover themselves. With this in mind, the figure below portrays proven means of settling contractual disputes.

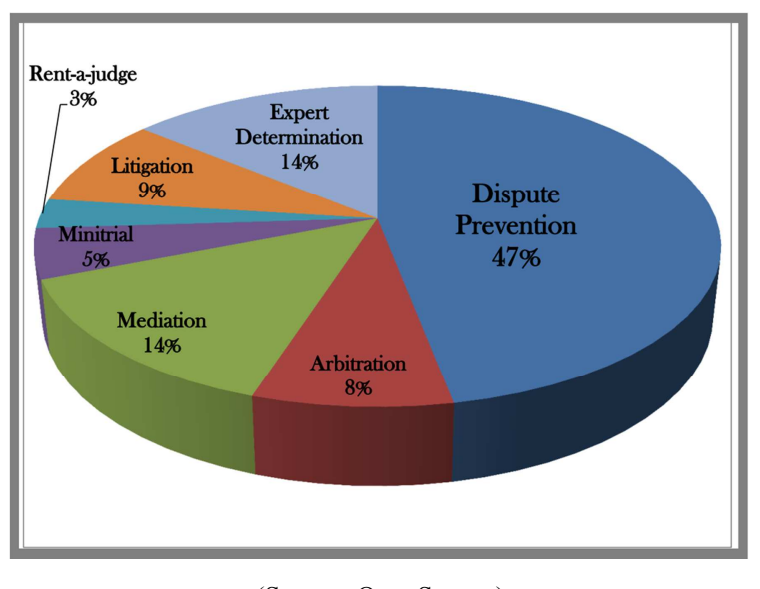

(Source: Own Survey)

Figure 8. Demonstrated dispute resolution mechanisms.

As shown on the figure above nearly half (47\%) of the respondents nominated dispute prevention as their tested and effective dispute resolution procedure. Contractual disputes are generally time-consuming, expensive and problematic. Often, they also damage relationships of the parties to the contract, and cause schedule and cost overruns. It is, therefore, in the best interest of the contracting parties to work at minimizing (and avoiding if possible) disputes in the first place. To minimize contractual disputes and subsequent complications, all parties involved therein would need to effectively carry out their duties consistent with the terms of the contract. This can be best achieved through putting dispute prevention mechanisms in place. At the outset, when contracting parties agree to put dispute-prevention processes in place, a progressive schedule of negotiation, mediation, and arbitration followed by litigation (as a last resort) is set and incorporated in the contractual agreement. As a result, disputes are settled well before they mature.

Finally, after extensive analysis of the data, operational techniques of using contract administration as a tool for successful project undertakings have emerged as the most attention worthy finding of this study.

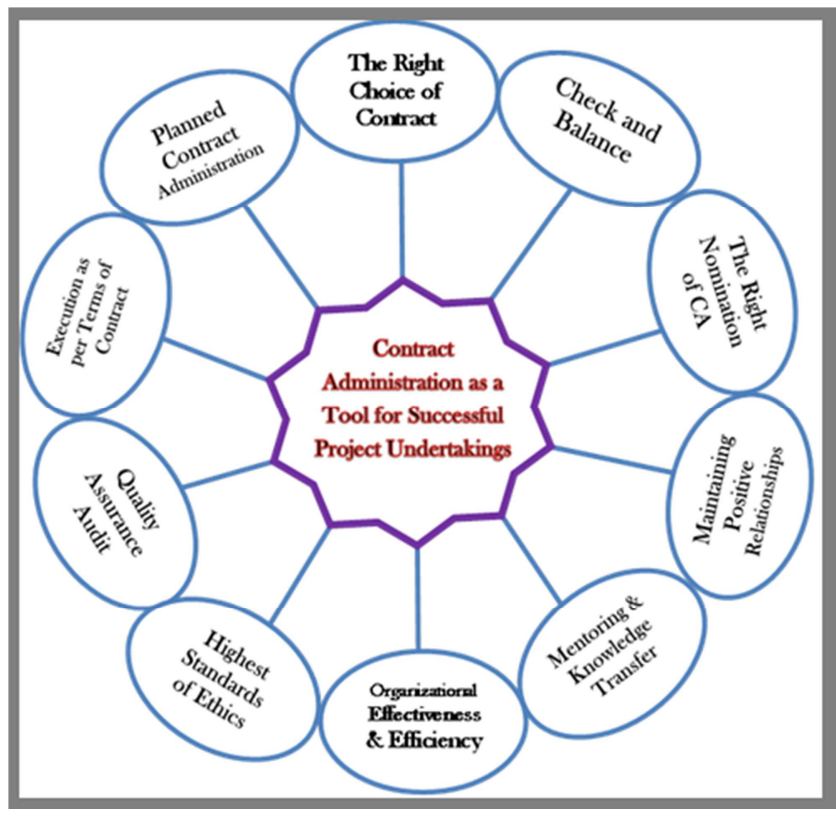

(Source: Own Survey)

Figure 9. Techniques of using contract administration as a tool for successful project undertakings.

The figure above is a diagrammatic representation of the top ten potential benefits and aids that can be harvested from good contract administration, as discovered by the data analysis effort of this study. It clearly revealed that contract administration can be used as an imperative tool for successful project undertakings as it offers the functions and benefits exhibited in the figure. In brief, contract administration plays, among others, the roles portrayed above which can significantly contribute to successful project undertakings. To sum up, given all the benefits of good contract administration, it is a phenomenal instrument for successful project undertakings.

\section{Conclusion}

In principle contract administration is a vibrant element of project management that has clearly articulated and communicated objectives, well-defined plan of activities and schedule of events, predetermined legal requirements and working frameworks, mindful assessment and management of any and all possible risks, wise allocation and use of human and material resources, strategically constructed means and methods of bringing objectives to reality thereby ensuring that 
project is built according to all contract provisions. Thus, the preponderant focus of contract administration is making sure that all the necessary resources and services that meet or exceed contract specifications are in place for the successful performance of projects.

Contract administration is a team work that requires collective efforts of all stakeholders concerned. Where a contract administration team is formed, a team leader (often called contract administrator) needs to be appointed with all and only the authority to manage the team and clear lines of reporting. The contract administrator is responsible to ensure that only professionals with the appropriate mix of skills are included in the team and are consulted as appropriate. Likewise, each individual team member has to demonstrate the skills, experience or knowledge that fits his/her particular role. Besides, each member of the team has to be in the physical and mental readiness to execute his/her responsibilities as required. In addition, each team member is accountable for his/her areas of responsibility.

Accordingly, successful contract administration is the upshot of responsible and effective teamwork which demands harmony among all stakeholders involved. However, because stakeholders often have conflicting interests, conflicts or disputes among stakeholders are likely to develop. Often with any common conditions of contract, the provisions that give rise to the most disputes are those that deal with budget and schedule of events.

Therefore, it is a sheer fact of the reality on the ground that contract administration protocol should be backed-up by all the appropriate terms of agreement it requires for its smooth accomplishment. Hence, contracts should set out the procedures to be used when a dispute arises. Most preferred dispute resolution strategies should also be clearly stated in any collaborative agreement. Then, given the most cost-effective dispute resolution mechanism, contracting parties should ensure that the mechanism is put in place in a timely manner so that they maintain their focus on the project. However, if disputes are left unresolved for any length of time, trust and commitment to the project will be compromised, and at the same time the long-term stability of the collaborative agreement could be at stake. Therefore, all contracting parties should do their level best to ensure that disputes are resolved as soon as detected; and the project is back on track for its final line or goal.

Generally, with comprehensive analysis of its data, this study has investigated fundamental considerations for the right choice of contract type; and possible techniques of using contract administration as a mechanism to mitigate fraud \& corruption. Most importantly, it has revealed tested and operational methods of using contract administration as a tool for successful project undertakings.

\section{Recommendations}

With all the research findings considered, the researcher of this study forwards the following recommendations for both practitioners and future researchers on the subject of this study.
1. As part of reducing likely disputes from their source, the terms and conditions of the contract have to be as clear and explicit as reasonably possible. The wordings of the contract matters!!!

2. When deciding dispute resolution mechanism, the status of the relationship between the parties in the dispute should be given paramount attention.

3. Since one measure of project success is clients' satisfaction, obtain contract administration inputs directly from the end users through the use of, for example, end user satisfaction surveys. This, as a result, helps to make ensure that the end users are satisfied with the product or service being obtained under the contract.

4. For effective contract administration, develop a master schedule and a work breakdown structure that incorporates every important date and/or milestone in the contract. Then, list contract deliverables and their evaluation criteria in detail with checklists for the people who perform the tasks.

5. The researcher also suggests further studies on how different styles of contract administration practices impact project success.

6. In conclusion, the researcher's final recommendation is deeper assessment of the effect of a contract administration protocol on mitigation of fraud and corruption.

\section{Declaration}

The author will not be liable or responsible for any loss or damage caused to any person acting or refraining from action as a result of the material included in this publication.

\section{References}

[1] Barratt M. and Rosdahl K.: Exploring Business-to-Business Marketsites, European Journal of Purchasing \& Supply Management 8 (2) 111-122, 2002.

[2] Benton, W. C., Linda McHenry (2010). Construction Purchasing \& Supply Chain Management, the McGraw-Hill Companies.

[3] Cary Cohen, Effective Contract Administration: The Complete Handbook and Guide, 1997.

[4] Cattani, G., Ferriani, S., Frederiksen, L. and Florian, T. (2011) Project-Based Organizing and Strategic Management, Advances in Strategic Management, Vol 28, Emerald, ISBN 1780521936.

[5] Cleland, David I. 2004. Field Guide to Project Management. $2^{\text {nd }}$ ed. John Wiley \& Sons, Inc.

[6] F. L. Harrison, Dennis Lock (2004). Advanced project management: a structured approach. Gower Publishing, Ltd., 2004. ISBN 0-566-07822-8.

[7] James P. Lewis (2000). The project manager's desk reference: a comprehensive guide to project planning, scheduling, evaluation, and systems. 
[8] Joseph Phillips (2003). PMP Project Management Professional Study Guide. McGraw-Hill Professional, 2003. ISBN 0-07-223062-2.

[9] Meredith, J. and Mantel, S. J. 2010. Project Management: A Managerial Approach. $7^{\text {th }}$ ed. John Wiley \& Sons, Inc.

[10] Paul A. Swegle, Contract Drafting and Negotiation for Entrepreneurs and Business Professionals, 2018.

[11] Paul C. Dinsmore et al (2005) The right projects done right! John Wiley and Sons, 2005. ISBN 0-7879-7113-8.
[12] PMI (2010). A Guide to the Project Management Body of Knowledge.

[13] Sunny and Baker, Kim. (2000). Project Management, 2nd ed. USA. Pearson Education, Inc.

[14] Telgen J.: Public Procurement Goes Electronic, Brussels, European Public Procurement Group, 2001.

[15] W. Hughes, R. Champion, J. Murdoch, "Construction Contracts: Law and Management”, 2015. 